\title{
Microbial Counts of Dried Powder Milk Available in Local Markets of Bangladesh
}

\author{
Salahudin Ahmed and M Nural Anwar* \\ Department of Microbiology, University of Chittagong, Chittagong 4331, Bangladesh
}

[Received 13 August 2006; Accepted 07 October 2006]

\begin{abstract}
This study reports on the microbiological status of dried milk samples belonging to eleven different companies. With few exceptions, the microbial counts of the milk samples were within the acceptable limits as specified by international authorities. Aerobic plate counts ranged from $1.4 \times 10^{1}-4.4 \times 10^{4} \mathrm{cfu} / \mathrm{g}$ and the number of Staphylococcus varied from $6.0 \times 10^{1}-8.2 \times 10^{2} \mathrm{cfu} / \mathrm{g}$. Presence of Staphylococcus in most of the samples indicates post-processing contamination of the milk. Coliform organisms and Salmonella were not detected from any of the samples tested. Yeasts or molds were found in the samples of four manufacturers but their counts were very low. Since the international agencies have not fixed any limit for Staphylococcus count in dry milk, the results of the present study indicate that powder milk products were of good quality from microbiological point of view.
\end{abstract}

Keywords: Dried milk, Microbial enumeration, Codex, ICMSF

Milk is the normal mammary secretion of milking animals obtained from one or more milking, intended for consumption as liquid milk or for further processing ${ }^{1}$. Dried milk defined as roller dried or spray dried milk product or composite milk product as mentioned in Codex dairy terms ${ }^{2}$. Actually liquid milk first concentrated and then the concentrated product leaving the evaporator in a drying plant and finally the dried milk product recovered. The quality of dried milk product greatly depends upon the microorganisms of liquid milk, while milk has a high nutritive value, not only for the newborn mammal and for the human consumer, but also for microbes $^{3}$. A variety of diseases are potentially transmissible through milk. Milk may be contaminated through infected cow having tuberculosis, brucellosis and mastitis and also from human carrier having typhoid fever, diphtheria, dysentery and scarlet fever ${ }^{4}$. Report available that dairy cattle and their firm's environments contain Listeria, Salmonella and pathogenic Eschericia coli ${ }^{5}$. Consumption of raw, or in adequately pasteurised milk also associated with toxin-producing E. coli, Salmonella and Listeria monocytogens ${ }^{6}$. Staphylococcus aureus can also present in the cows udder and teats and consequently contaminate the milk ${ }^{7}$. However, it is recommended by the Codex Alimentarius Commission $^{2}$ that all milk and liquid product should be pasteurised prior to concentration before drying, but inadequate pasteurisation may facilitate the survival of bacterial pathogen in dried milk.

Outbreaks of staphylococcal food poisoning from reconstitute powdered milk from a powdered malted milk have also been reported $^{8}$, and hence Codex Alimentarius Commission ${ }^{2}$ established recommended international code of hygienic practice for dried milk including processing instruction and microbiological criteria. Other microbiological criteria are also available for dried milk from International Commission on Microbiological Specification for Foods ${ }^{9}$. Actually, in our country, milk powder is used for many purposes including making ice cream, curd, custard, pudding and other milk-based food preparation irrespective of its use in normal liquid milk preparation and even for the preparation of infant food in some instance. No recent data are available in our country about the microbiological quality of dried milk powder, while some reports are available on the prevalence of microbial contamination of liquid milk and milk product ${ }^{10}$. In view of the above, a microbiological study had been conducted in order to investigate the microbiological quality of dry milk powder that are available in local market of Bangladesh.

Powered milk samples from 11 companies were collected, following standard sampling method ${ }^{2}$ and sampling plan ${ }^{9}$, for microbiological analyses. Aerobic plate count, Staphylococcus count, total coliform count, Salmonella detection, and yeast and mold counts were performed using the procedures described by the ICMSF${ }^{8}$. Aerobic plate count and Staphylococcus count were carried out respectively on plate count agar (PCA) and Baird Parker agar (BPA). The agar plates were incubated aerobically at $37^{\circ} \mathrm{C}$ for $48 \mathrm{~h}$ and the colonies developed were counted. On BPA plates, black and shiny colonies with narrow white margin and with or without clear zone in the medium surrounding the colonies were

${ }^{*}$ Corresponding author:

Dr. M Nural Anwar, Professor, Department of Microbiology, University of Chittagong, Chittagong 4331, Bangladesh

Tel (Office): (031) 682031-39/4464; Tel (Home): (031) 681688; Fax: +880 (031) 726310; E-mail: anwarmn54@yahoo.com 
considered as colonies of Staphylococcus. The most probable number (MPN) method was used for the enumeration of total coilforms using lauryl sulphate tryptose (LST) broth medium. The cultures showing gas production in LST broth after incubation at $35-37^{\circ} \mathrm{C}$ for $48 \mathrm{~h}$ was transferred to brilliant green lactose bile (BGLB) broth. Gas production in 2\% BGLB broth was considered as positive for coliform. Number of coliforms was recorded from the MPN chart. For isolation and enrichment of Salmonella from the milk samples, lactose broth was initially used as a non-selective enrichment medium. After incubation at $37^{\circ} \mathrm{C}$ for $24 \mathrm{~h}$ in lactose broth, the culture $(1 \mathrm{ml})$ was transferred into tubes containing selenite cystine broth and tetrathioate broth media, and subsequently incubated at $43^{\circ} \mathrm{C}$ for $24 \mathrm{~h}$. The cultures grown were then streaked on brilliant green agar (BGA) and bismuth sulphite agar (BSA) media. After incubation at $35-37^{\circ} \mathrm{C}$ for $48 \mathrm{~h}$, typical and atypical colonies were picked up and salmonellae were identified on the basis of biochemical changes in triple sugar iron (TSI) agar and lysine iron agar (LIA) tubes. For the isolation and enumeration of yeasts and molds, oxytetracycline gentamicin yeast extract glucose (OGY) agar medium was used. The agar plates were incubated at $20-24^{\circ} \mathrm{C}$ for $3-5$ days.

Table 1 summarizes the results of microbiological analyses of representative five powder milk samples from each of the eleven different manufacturers. The aerobic plate counts ranged from $1.4 \times 10^{1}-4.4 \times 10^{4} \mathrm{cfu} / \mathrm{g}$. According to the Codex Alimentarius
Commission guideline ${ }^{1}$, the dried milk powder should contain less than $5.0 \times 10^{4} \mathrm{cfu} / \mathrm{g}$. According to the specification given by the ICMSF $^{9}$, it should be less than $3.0 \times 10^{4} \mathrm{cfu} / \mathrm{g}$. In this study, aerobic plate counts for most of the samples were within the acceptable limit of the Codex ${ }^{1}$ or the $\mathrm{ICMSF}^{9}$. Moreover, none of the aerobic plate count results exceeded the marginally acceptable limit of the Codex $\left(3.0 \times 10^{5} \mathrm{cfu} / \mathrm{g}\right)$ and the ICMSF $\left(2.0 \times 10^{5} \mathrm{cfu} / \mathrm{g}\right)$ specifications. Boor et al. ${ }^{11}$ reported a total bacterial load of $1.1 \mathrm{x}$ $10^{4} \mathrm{cfu} / \mathrm{ml}$ in raw milk. Staphylococcus counts in this study ranged between $6.0 \times 10^{1}$ and $8.2 \times 10^{2} \mathrm{cfu} / \mathrm{g}$. There is no specification yet been set by the Codex or the ICMSF in this regard, however, the presence of high number of staphylococci in dry powder milk indicates poor post-processing sanitation since their presence is often used as a post-processing hygienic indicator ${ }^{8}$. Many reports are available on the staphylococcal milk contamination ${ }^{12-14}$. In this study, coliforms were not found in any sample of the samples tested. Coliform organisms in dried milk powder might die out during processing and storage ${ }^{9}$. Salmonella was also identified from any of the samples tested using the standard procedure ${ }^{8}$. There are reports on Salmonella contamination in bulk tank milk ${ }^{5}$. Milas ${ }^{15}$ reported on rapid detection of Salmonella in dried milk products by motility enrichment on modified semisolid RappaportVassiliadis medium. Yeasts and molds were found in the samples of four companies. Their presence in milk or milk products is usually considered as spoilage agents.

Table 1. Average microbiological counts of dried milk powder samples from eleven companies

\begin{tabular}{|c|c|c|c|c|c|}
\hline $\begin{array}{l}\text { Milk source } \\
\text { coded }^{\mathrm{a}}\end{array}$ & $\begin{array}{c}\text { Aerobic plate count } \\
(\mathrm{cfu} / \mathrm{g})\end{array}$ & $\begin{array}{c}\text { Staphylococcus } \\
\text { (cfu/g) }\end{array}$ & $\begin{array}{l}\text { Total coliform } \\
(\mathrm{MPN} / \mathrm{g})^{\mathrm{b}}\end{array}$ & $\begin{array}{c}\text { Salmonella } \\
\text { (per } 25 \mathrm{~g} \text { ) }\end{array}$ & $\begin{array}{c}\text { Yeast/mold } \\
(\mathrm{cfu} / \mathrm{g})\end{array}$ \\
\hline $\mathrm{DN}$ & $1.5 \times 10^{3}-2.0 \times 10^{3}$ & $2.0 \times 10^{2}-4.1 \times 10^{2}$ & $<3$ & 0 & 0 \\
\hline MRK & $1.0 \times 10^{2}-6.0 \times 10^{3}$ & $1.3 \times 10^{2} 15.3 \times 10^{2}$ & $<3$ & 0 & 0 \\
\hline FRS & $2.0 \times 10^{3}-4.4 \times 10^{4}$ & $1.7 \times 10^{2}-5.0 \times 10^{2}$ & $<3$ & 0 & 0 \\
\hline FRL & $2.0 \times 10^{3}-3.0 \times 10^{3}$ & $1.1 \times 10^{2}-2.8 \times 10^{2}$ & $<3$ & 0 & $0-20$ \\
\hline DLM & $2.0 \times 10^{3}-3.5 \times 10^{4}$ & $8.0 \times 10^{1}-7.1 \times 10^{2}$ & $<3$ & 0 & 0 \\
\hline ACR & $1.2 \times 10^{3}-2.0 \times 10^{3}$ & $1.4 \times 10^{2}-2.2 \times 10^{2}$ & $<3$ & 0 & $0-5$ \\
\hline RDC & $1.7 \times 10^{1}-2.2 \times 10^{2}$ & $6.0 \times 10^{1}-2.2 \times 10^{2}$ & $<3$ & 0 & 0 \\
\hline QLT & $1.5 \times 10^{2}-2.8 \times 10^{3}$ & $1.8 \times 10^{2}-7.5 \times 10^{2}$ & $<3$ & 0 & $0-10$ \\
\hline DNS & $1.1 \times 10^{1}-2.7 \times 10^{2}$ & $1.2 \times 10^{2}-5.2 \times 10^{2}$ & $<3$ & 0 & 0 \\
\hline
\end{tabular}

aFive samples were tested from each brand. ${ }^{b} \mathrm{~A}$ most probable number (MPN) value less than 3/g indicates the absence of coliform organisms. 
It was apparent from the present study that microbiological quality of the dry milk products was acceptable although most of the samples tests were contaminated with Staphylococcus. The international agencies like the Codex and the ICMSF did not fix any limit for Staphylococcus in dry milk. Therefore, it could be assume that the manufacturers of powder milk products are maintaining good personal hygiene and sanitation conditions in their processing units. Since, powder milk is consumed mainly by children in Bangladesh, therefore, a Standard Sanitation Operating Procedure (SSOP) should be maintained, which is a prerequisite program of Hazard Analysis and Critical Control Point (HACCP), in order to minimize the risk of contamination for safety purpose.

\section{References}

1. Codex. 1999. Codex General Standard for the Use of Dairy Terms, Codex Standard 206-1999. Codex Alimentarius Commission. Food \& Agriculture Organization (FAO), Rome.

2. Codex. 1983. Recommended International Code of Hygienic Practice for Dried Milk, CAC/RCP, 31-1983. Codex Alimentarius Commission. Food \& Agriculture Organization (FAO), Rome.

3. Wouters JTM, Ayad EHE, Hugenholtz J \& Smil G. 2002. Microbes from raw milk for fermented dairy products. Int Dairy J. 12(2-3): 91109.

4. Pelczar MJ, Chan ECS \& Krieg NR. 1993. Microbiology, $5^{\text {th }}$ edn. Tata McGraw Hill Publishing Co Ltd, New Delhi.

5. Kessel JSV, Karns JS, Gorski L, McCluskey BJ \& Perdue ML. 2004. Prevalence of Salmonella, Listeria monocytogenes and faecal coliform in bulk tank milk on US daires. J Dairy Sci. 87: 2822-2830.

6. Jayaro BM \& Henning DR. 2001. Prevalence of food-borne pathogens in bulk tank milk. J Dairy Sci. 84: 2157-2162.
7. Tahiri R. 2005. A comparison on microbial conditions between traditional dairy products sold in Karak and same products produced by modern dairies. Pakistan J Nutr. 4(5): 345-348.

8. ICMSF. 1978. Microorganisms in Foods. 1. Their Significance and Methods of Enumeration, $2^{\text {nd }}$ edn. International Commission on Microbiological Specifications for Foods (ICMSF). University of Toronto Press, Toronto.

9. ICMSF. 1986. Microorganisms in Foods. 2. Sampling for Microbiological Analysis: Principles and Specific Applications, $2^{\text {nd }}$ edn. University of Toronto Press, Toronto.

10. Bashar T \& Malek MA. 2006. Prevalence of microbial contaminants of some milk and milk products available in different markets of Dhaka. Bangladesh J Microbiol. 23(1): 75-77.

11. Boor KJ, Brown DP, Murphy SC, Kozlowski SM \& Bandler DK. 1998. Microbiological and chemical quality of raw milk in New York State. J Dairy Sci. 81: 1743-1748.

12. Desmasures N \& Gueguen M. 1997. Monitoring the microbiology of high quality milk by monthly sampling over 2 years. J Dairy Res. 64: 271-280.

13. Jorgensen HJ, Mork T, Hogasen HR \& Rorvik LM. 2005. Enterotoxigenic Staphylococcus aureus in bulk milk in Norway. J Appl Microbiol. 99(1): 158-166.

14. Banfoh B, Wasem A, Traore AN, Fane A, Spillmann H, Simbe CF, Alfaroukh IO, Nicolet J, Farah Z \& Zinsstag J. 2003. Microbiological quality of cow's milk taken at different intervals from the udder to the selling point in Bamako (Mali). Food Control. 14: 495-500.

15. Milas JE. 1996. Salmonella detection in dried milk products by motility enrichment on modified semisolid Rappaport-Vassiliadis medium: Collaborative study. J AOAC Int. 79(2): 441-450. 